\title{
SOLUTION OF THE SYNTHESIS PROBLEM OF BOUNDARY OPTIMAL CONTROL OF A ROD COOLING PROCESS WITH A HEAT CONDUCTIVE VISCOSITY
}

\author{
Mammadov Rashad Sirac \\ Department of General and Applied Mathematics \& quot \\ Azerbaijan State University of Oil and Industry \\ 20 Azadlig ave., Baku, Azerbaijan, AZ1010 \\ Rasadmammadov@mail.ru \\ Qasimov Sardar Yusub \\ Department of General and Applied Mathematics \& quot \\ Azerbaijan State University of Oil and Industry \\ 20 Azadlig ave., Baku, Azerbaijan, AZ1010 \\ sardarkasumov1955@mail.ru
}

\begin{abstract}
The problem of synthesis of the boundary optimal control of the cooling process of media with heat conductive viscosity is investigated. In addition to the distributed parameters, the concentrated parameters act on the system. This is due to the fact that the temperature of the external environment is unknown and varies according to a given law. As a result, the process is described by a system of partial differential equations and ordinary differential equations. In this case, heat transfer occurs at the right end of the rod. This complicates the obtaining of a solution of this boundary-value problem in an explicit form. But it is possible to establish the existence and uniqueness of the solution of the corresponding boundary-value problem for concrete admissible controls.

The criterion of quality is a quadratic functional and it is required to build control in the form of feedback. First by the Fourier method, the problem under consideration is formulated in an infinite-dimensional phase space. As a result, the problem of synthesis of optimal control in a functional space is obtained. To solve this problem, the dynamic programming method is used. To do this, let's introduce the Bellman functional and obtain the Bellman equation, which this functional satisfies. The solution of this equation allows to find the control parameter in the form of a functional defined on the set of the state function. Further, by introducing the corresponding functions, feedback control is constructed for the original problem. Unlike program control, this allows to influence the behavior of the system at any time, that is, to ensure the self-regulation of the process. However, let's note that the difficulties in solving this problem are connected with the justification of the proposed method. This is established by the investigation of a closed system.

Keywords: controlled object, feedback, Fourier series, dynamic programming method, Bellman functional, functional gradient, admissible control, Bellman equation.
\end{abstract}

\section{Introduction}

If the material does not have a conductive viscosity, the process of heat or cooling transfer is described by a parabolic equation. The problem of synthesis of optimal control of such systems has been studied sufficiently [1-6]. Since in a material with a heat-conducting viscosity the temperature gradient changes along the direction of heat transfer, the cooling process is described by a partial differential equation of higher order $[7,8]$.

In [7], the solvability of the boundary value problem corresponding to this type of process is investigated. And in [8] the problem of synthesizing the optimal control of this process is solved, when the control parameter is distributed.

But if there are external control parameters in the process of heat conduction, then the process is described by a set of equations in partial and ordinary derivatives [9-11]. The difficulty in solving the synthesis problem of optimal control in this case is due to the fact that it is not possible to find an explicit solution of the corresponding boundary-value problem. In addition, the closed system is solvable and ensures the self-regulation of the corresponding process.

The obtained results relate to the problems of optimal control with systems containing elements with distributed parameters, and they can be applied to the process of heating and cooling the material with the minimum energy expenditure. 


\section{Problem statement}

Let the state of the controlled object be described by a vector function $\bar{u}(x, t)=(y(t), u(x, t))$ and $\mathrm{u}(\mathrm{x}, \mathrm{t})$ within the range $\overline{\mathrm{Q}}=[0, \mathrm{~T}] \times[0,1]$ satisfies equation

$$
\frac{\partial u}{\partial t}=a^{2} \frac{\partial^{2} u}{\partial x^{2}}+\xi \frac{\partial^{3} u}{\partial t \partial x^{2}}+p(x, t)
$$

with initial and boundary conditions

$$
\begin{gathered}
u(x, 0)=u^{0}(x), \\
\frac{\partial u(0, t)}{\partial x}=0, \frac{\partial u(1, t)}{\partial x}+\alpha u(1, t)=y(t),
\end{gathered}
$$

where a, $\alpha>0$ - the real constant, $\xi=$ const $>0$ - the coefficient of heat conductive viscosity, $\mathrm{u}^{0}(\mathrm{x})$ - the given function of $\mathrm{W}_{2}^{1}(0,1)$ and $\mathrm{p}(\mathrm{x}, \mathrm{t})$ - distributed control function.

An unknown function $y(t)$ occurring in condition (3) is assumed to satisfy equation

$$
\frac{d y}{d t}=a_{0} u(1, t)+b y+p_{0}(t)
$$

with the initial condition

$$
\mathrm{y}(0)=\mathrm{y}^{0},
$$

where $\mathrm{a}_{0} \neq 0, \mathrm{~b}$ and $\mathrm{y}^{0}-$ given real numbers, and $\mathrm{p}_{0}(\mathrm{t})$ - concentrated control function.

A vector-valued function $\bar{p}(x, t)=\left(p_{0}(t), p(x, t)\right)$ will be called an admissible control if $\mathrm{p}_{0}(\mathrm{t}) \in \mathrm{L}_{2}(0, \mathrm{~T}), \mathrm{p}(\mathrm{x}, \mathrm{t}) \in \mathrm{L}_{2}(\mathrm{Q})$.

The optimal control problem under consideration consists in finding an admissible control in the form of feedback $\overline{\mathrm{p}}[\mathrm{x}, \mathrm{t}, \overline{\mathrm{u}}]$, such that the functional

$$
\begin{aligned}
\mathrm{I}[\overline{\mathrm{p}}]= & \beta_{0} \mathrm{y}^{2}(\mathrm{~T})+\beta \int_{0}^{1}[\mathrm{u}(\mathrm{x}, \mathrm{T})-\psi(\mathrm{x})]^{2} \mathrm{dx}+ \\
& +\gamma_{0} \int_{0}^{\mathrm{T}} \mathrm{p}_{0}^{2}(\mathrm{t}) \mathrm{dt}+\gamma \int_{0}^{\mathrm{T}} \int_{0}^{1} \mathrm{p}^{2}(\mathrm{x}, \mathrm{t}) \mathrm{dxdt}
\end{aligned}
$$

take the smallest possible value. Here $\beta_{0}, \beta=$ const $\geq 0, \beta_{0}+\beta \neq 0 ; \gamma_{0}, \gamma=$ const $>0 ; \mathrm{T}-\mathrm{a}$ fixed time and $\psi(\mathrm{x}) \in \mathrm{W}_{2}^{1}(0,1)-$ a given function.

It can be established that for each particular admissible control $\bar{p}(x, t)=\left(p_{0},(t), p(x, t)\right)$ there exists a unique generalized solution $\overline{\mathrm{u}}(\mathrm{x}, \mathrm{t})=(\mathrm{y}(\mathrm{t}), \mathrm{u}(\mathrm{x}, \mathrm{t}))$ of the boundary value problem (1)-(5) having the following properties:

1) $y(t) \in H^{1}(0, T), u(x, t) \in V_{2}^{1,0}(Q)$

2) for any function $\Phi(x, t) \in W_{2}^{1,1}(Q)$ that equal to zero for $t=T$, there is an integral identity

$$
\begin{gathered}
\int_{0}^{\mathrm{T}} \int_{0}^{1}\left[-\mathrm{u}(\mathrm{x}, \mathrm{t}) \Phi_{\mathrm{t}}+\mathrm{a}^{2} \mathrm{u}_{\mathrm{x}} \Phi_{\mathrm{x}}\right] \mathrm{dxdt}+\alpha \mathrm{a}^{2} \int_{0}^{\mathrm{T}} \mathrm{u}(1, \mathrm{t}) \Phi(1, \mathrm{t}) \mathrm{dt}+ \\
+\mathrm{a}^{2} \int_{0}^{\mathrm{T}} \mathrm{y}(\mathrm{t}) \Phi(1, \mathrm{t}) \mathrm{dt}=\int_{0}^{1} \mathrm{u}^{0}(\mathrm{x}) \Phi(\mathrm{x}, 0) \mathrm{dx}+\int_{0}^{1} \Phi_{\mathrm{x}}(\mathrm{x}, 0) \mathrm{u}_{\mathrm{x}}^{0}(\mathrm{x}) \mathrm{dx}-\left[\mathrm{y}^{0}-\alpha \mathrm{u}^{0}(1)\right] \Phi(1,0)+ \\
+\int_{0}^{\mathrm{T}} \int_{0}^{1} \mathrm{p}(\mathrm{x}, \mathrm{t}) \mathrm{dxdt} ;
\end{gathered}
$$


3) the functions $y(t)$ and $u(x, t)$ satisfy the integral equation

$$
y(t)=y^{0}+\int_{0}^{t}\left[a_{0} u(1, \tau)+b y(\tau)+p_{0}(\tau)\right] d \tau
$$

For all $\mathrm{t} \in[0, \mathrm{~T}]$.

\section{Problem statement in an infinite-dimensional phase space}

Let's consider in $\mathrm{L}_{2}(0,1)$ an orthonormal system of functions

$$
X_{n}(x)=\frac{\cos \lambda_{n} x}{\sqrt{\omega_{n}}}, n=1,2, \ldots
$$

where $\lambda_{n}$ - eigenvalues of the boundary value problem

$$
\mathrm{X}^{\prime \prime}(\mathrm{x})+\lambda^{2} \mathrm{X}(\mathrm{x})=0, \quad 0<\mathrm{x}<1 ; \quad \mathrm{X}^{\prime}(0)=0, \quad \mathrm{X}^{\prime}(1)+\alpha \mathrm{X}(1)=0
$$

which are positive roots of the equation $\lambda \operatorname{tg} \lambda=\alpha$, and $\omega_{n}=\frac{\alpha+\alpha^{2}+\lambda_{n}^{2}}{2\left(\alpha^{2}+\lambda_{n}^{2}\right)}-$ normalizing factor.

The solution of problem (1)-(3) will be sought in the form of a Fourier series

$$
u(x, t)=\sum_{k=1}^{\infty} u_{k}(t) X_{k}(x), \quad u_{k}(t)=\int_{0}^{1} u(x, t) X_{k}(x) d x
$$

Let's multiply both sides of equation (1) by $\mathrm{X}_{\mathrm{k}}(\mathrm{x})$ and integrate along $\mathrm{x}$ from 0 to 1 .

Taking into account (2)-(5) and (9), let's obtain an infinite system of ordinary differential equations for determining the function and the coefficients $y_{k}(t), k=1,2, \ldots$ :

$$
\left\{\begin{array}{l}
\frac{d y(t)}{d t}=b y(t)+a_{0} \sum_{k=1}^{\infty} X_{k}(1) u_{k}(t)+p_{0}(t) \\
\frac{d u_{k}(t)}{d t}=-a^{2} X_{k}(1) y(t)-\frac{a^{2} \lambda_{k}^{2}}{1+\xi \lambda_{k}^{2}} u_{k}(t)+p_{k}(t),
\end{array}\right.
$$

with initial conditions

$$
\mathrm{y}(0)=\mathrm{y}^{0}, \quad \mathrm{u}_{\mathrm{k}}(0)=\mathrm{u}_{\mathrm{k}}^{0}, \mathrm{k}=1,2, \ldots
$$

where $p_{k}(t)$ and $u_{k}^{0}-$ Fourier coefficients of the functions $p(x, t)$ and $u^{0}(x)$.

Taking into account the orthonormality of the system of functions $\left\{\mathrm{X}_{\mathrm{k}}(\mathrm{x})\right\}$, the functional (6) can be represented in the form

$$
\begin{gathered}
\mathrm{I}_{\infty}\left[\mathrm{p}_{0}, \mathrm{p}_{1}, \ldots\right]=\beta_{0} \mathrm{y}^{2}(\mathrm{~T})+\beta \sum_{\mathrm{k}=1}^{\infty}\left[\mathrm{y}_{\mathrm{k}}(\mathrm{T})-\psi_{\mathrm{k}}\right]^{2}+ \\
\quad+\gamma_{0} \int_{0}^{\mathrm{T}} \mathrm{p}_{0}^{2}(\mathrm{t}) \mathrm{dt}+\gamma \int_{0}^{\mathrm{T}} \sum_{\mathrm{k}=1}^{\infty} \mathrm{p}_{\mathrm{k}}^{2}(\mathrm{t}) \mathrm{dt}
\end{gathered}
$$

where $\psi_{\mathrm{k}}-$ the Fourier coefficients of the function. 
Thus, the optimal control problem reduces to finding in the class of admissible controls such control $\left(\mathrm{p}_{0}\left[\mathrm{t}, \mathrm{y}(\mathrm{t}), \mathrm{y}_{1}(\mathrm{t}), \ldots\right], \mathrm{p}_{1}[\mathrm{t}, \mathrm{y}(\mathrm{t}), \ldots], \ldots\right)$ and the corresponding solutions $\left(\mathrm{y}(\mathrm{t}), \mathrm{u}_{1}(\mathrm{t}), \mathrm{u}_{2}(\mathrm{t}), \ldots\right)$ of the problem (11)-(12) in the form of feedback so that the functional (13) takes the smallest possible value.

For the obtained optimal control problem, the class of admissible controls consists of infinite-dimensional vector-valued functions $\left(\mathrm{p}_{0}(\mathrm{t}), \mathrm{p}_{1}(\mathrm{t}), \mathrm{p}_{2}(\mathrm{t}), \ldots\right)$ satisfying condition

$$
\int_{0}^{\mathrm{T}} \sum_{\mathrm{k}=0}^{\infty} \mathrm{p}_{\mathrm{k}}^{2}(\mathrm{t}) \mathrm{dt}<\infty
$$

Let's introduce the following infinite-dimensional vectors and matrices:

$$
\begin{aligned}
& \bar{y}(t)=\left\{y(t), u_{1}(t), u_{2}(t), \ldots\right\}, \overline{y^{0}}=\left\{y^{0}, u_{1}^{0}, u_{2}^{0}, \ldots\right\}, \\
& \overline{\mathrm{p}}(\mathrm{t})=\left\{\sqrt{\frac{\gamma_{0}}{\gamma}} \mathrm{p}_{0}(\mathrm{t}), \mathrm{p}_{1}(\mathrm{t}), \mathrm{p}_{2}(\mathrm{t}), \ldots\right\}, \quad \bar{\psi}=\left\{0, \psi_{1}, \psi_{2}, \ldots\right\}, \\
& \mathrm{Q}=\operatorname{diaq}\left[\beta_{0}, \beta, \beta, \ldots\right], \quad \mathrm{B}=\operatorname{diaq}\left[\sqrt{\frac{\gamma}{\gamma_{0}}}, 1,1, \ldots\right],
\end{aligned}
$$

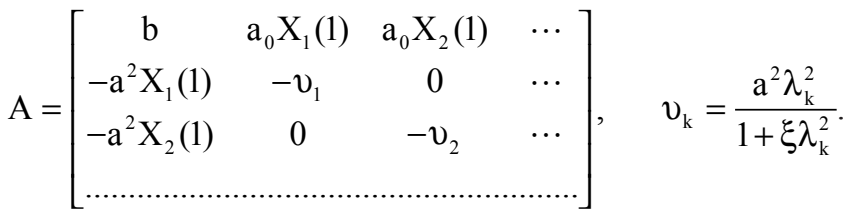

Using this notation, the problem (11), (12) with the quality criterion (13) can be represented in the following matrix form:

$$
\begin{gathered}
\frac{\mathrm{dy}}{\mathrm{dt}}=\mathrm{A} \overline{\mathrm{y}}+\mathrm{B} \overline{\mathrm{p}}, \quad 0<\mathrm{t} \leq \mathrm{T}, \\
\overline{\mathrm{y}}(0)=\overline{\mathrm{y}}^{0} ; \\
\mathrm{I}_{\infty}[\overline{\mathrm{p}}]=[\overline{\mathrm{y}}(\mathrm{T})-\bar{\psi}]^{*} \mathrm{Q}[\overline{\mathrm{y}}(\mathrm{T})-\bar{\psi}]+\gamma \int_{0}^{\mathrm{T}} \overline{\mathrm{p}}^{2}(\mathrm{t}) \mathrm{dt} .
\end{gathered}
$$

\section{Application of the dynamic programming method}

To solve the optimal control problem formulated above, under the constraints (16), (17) with the quality criterion (18), let's use the dynamic programming method. Following [3], let's introduce the Bellman functional

$$
\mathrm{S}[\mathrm{t}, \overline{\mathrm{y}}]=\min _{\substack{\mathrm{p}\{\tau\} \\ \mathrm{t} \leq \tau \leq \mathrm{T}}}\left([\overline{\mathrm{y}}(\mathrm{T})-\bar{\psi}]^{*} \mathrm{Q}[\overline{\mathrm{y}}(\mathrm{T})-\bar{\psi}]+\gamma \int_{\mathrm{t}}^{\mathrm{T}} \overline{\mathrm{p}}^{2}(\tau) \mathrm{d} \tau\right.
$$

Carrying out the well-known procedure of the dynamic programming method [3], let's obtain the Bellman equation: 


$$
-\frac{\partial S}{\partial t}=\min _{\bar{p}(t)}\left\{\gamma \bar{p}^{2}(t)+\frac{S^{*}}{\partial \bar{y}}[A \bar{y}(t)+B \bar{p}(t)]\right\} .
$$

It follows directly from the definition of the functional $S$ by formula (19) that $S \geq 0$ and

$$
\mathrm{S}[\mathrm{T}, \overline{\mathrm{y}}(\mathrm{T})]=[\overline{\mathrm{y}}(\mathrm{T})-\bar{\psi}]^{*} \mathrm{Q}[\overline{\mathrm{y}}(\mathrm{T})-\bar{\psi}]
$$

Thus, the solution of the optimal control problem is reduced to the definition of $\bar{p}(t)$ and nonnegative $\mathrm{S}[\mathrm{t}, \overline{\mathrm{y}}]$ from equation (20) with the additional condition (21).

Let's suppose that admissible controls are arbitrary vector-valued functions satisfying condition (14). Then from the expression on the right-hand side of the Bellman equation, let's find that

$$
\bar{p}(t)=-\frac{1}{2 \gamma} B^{*} \frac{\partial S}{\partial t}
$$

Eliminating $\bar{p}(t)$ from equation (20), let's obtain

$$
-\frac{\partial \mathrm{S}}{\partial \mathrm{t}}=-\frac{1}{4 \gamma} \frac{\partial \mathrm{S}^{*}}{\partial \overline{\mathrm{y}}} \mathrm{BB}^{*} \frac{\partial \mathrm{S}}{\partial \overline{\mathrm{y}}}+\frac{\partial \mathrm{S}^{*}}{\partial \overline{\mathrm{y}}} \cdot \mathrm{A} \overline{\mathrm{y}} .
$$

The solution of this functional equation will be sought in the quadratic form

$$
\mathrm{S}[\mathrm{t}, \overline{\mathrm{y}}]=[\overline{\mathrm{y}}(\mathrm{t})-\bar{\psi}]^{*} \mathrm{~K}(\mathrm{t})[\overline{\mathrm{y}}(\mathrm{t})-\bar{\psi}]+2 \phi^{*}(\mathrm{t})[\overline{\mathrm{y}}(\mathrm{T})-\psi]+\eta(\mathrm{t})
$$

where $\mathrm{K}(\mathrm{t})=\left\{\mathrm{K}_{\mathrm{ij}}(\mathrm{t})\right\}_{\mathrm{i}, \mathrm{j}=0}^{\infty}-$ an infinite-dimensional symmetric matrix-function, $\bar{\phi}(\mathrm{t})=\left\{\phi_{\mathrm{i}}(\mathrm{t})\right\}_{\mathrm{i}=0}^{\infty}-$ an infinite-dimensional vector-valued function, $\eta(\mathrm{t})$ - a scalar function that are to be determined. They are found from the condition that the functional $\mathrm{S}$ defined by (24) satisfies equation (23).

Let's note that $\mathrm{K}(\mathrm{t})$ must be a non-negative definite matrix for any $\mathrm{t} \in[0, \mathrm{~T}]$.

Calculating the gradient of the functional (24), let's find that

$$
\frac{\partial \mathrm{S}}{\partial \overline{\mathrm{y}}}=2 \mathrm{~K}(\mathrm{t})[\overline{\mathrm{y}}(\mathrm{t})-\bar{\psi}]+2 \bar{\phi}(\mathrm{t})
$$

Substituting this value in (23) and taking into account that the resulting equality must be satisfied for any vector function $\bar{y}(\mathrm{t})$, let's obtain:

$$
\begin{gathered}
\frac{\mathrm{d}}{\mathrm{dt}} \mathrm{K}(\mathrm{t})=-\mathrm{A}^{*} \mathrm{~K}(\mathrm{t})-\mathrm{K}(\mathrm{t}) \mathrm{A}+\frac{1}{\gamma} \mathrm{K}(\mathrm{t}) \mathrm{BB}^{*} \mathrm{~K}(\mathrm{t}), \\
\frac{\mathrm{d}}{\mathrm{dt}} \phi(\mathrm{t})=-\left[-\mathrm{A}^{*}+\frac{1}{\gamma} \mathrm{B}^{*} \mathrm{~K}(\mathrm{t})\right] \phi(\mathrm{t})-\mathrm{K}(\mathrm{t}) \mathrm{A} \psi, \\
\frac{\mathrm{d}}{\mathrm{dt}} \eta(\mathrm{t})=-\frac{1}{\gamma} \phi^{2}(\mathrm{t})-2 \phi^{*}(\mathrm{t}) \mathrm{A} \bar{\psi} .
\end{gathered}
$$

From condition (21) and formula (24):

$$
\mathrm{K}(\mathrm{T})=\mathrm{Q}, \quad \phi(\mathrm{T})=0, \quad \eta(\mathrm{T})=0 .
$$


Thus, if the matrix $\mathrm{K}(\mathrm{T})$ is determined from (26), then the vector $\phi(\mathrm{t})$ is determined from (27). After these functions can be determined, $\eta(t)$ is found from (28). This makes it possible to find the Fourier coefficients for the control function.

\section{Construction of control in the form of feedback}

Since the gradient of the functional (21) is calculated by the formula (22), then from (19) let's determine the optimal control in the form

$$
\overline{\mathrm{p}}(\mathrm{t})=-\frac{1}{\gamma} \mathrm{B}^{*} \mathrm{~K}(\mathrm{t}) \overline{\mathrm{y}}(\mathrm{t})-\frac{1}{\gamma} \mathrm{B}^{*}[\phi(\mathrm{t})-\mathrm{K}(\mathrm{t}) \bar{\psi}]
$$

or passing to coordinate notations

$$
\left\{\begin{array}{l}
p_{0}(t)=-\frac{1}{\sqrt{\gamma_{0} \gamma}} \mathrm{K}_{00}(\mathrm{t}) \mathrm{y}(\mathrm{t})-\frac{1}{\sqrt{\gamma_{0} \gamma}} \sum_{\mathrm{j}=1}^{\infty} \mathrm{K}_{0 \mathrm{j}}(\mathrm{t}) \mathrm{u}_{\mathrm{j}}(\mathrm{t})+\frac{1}{\sqrt{\gamma_{0} \gamma}}\left(-\phi_{0}(\mathrm{t})+\sum_{\mathrm{j}=1}^{\infty} \mathrm{K}_{0 \mathrm{j}}(\mathrm{t}) \psi_{\mathrm{j}}\right), \\
\mathrm{p}_{\mathrm{i}}(\mathrm{t})=-\frac{1}{\gamma} \mathrm{K}_{\mathrm{i} 0}(\mathrm{t}) \mathrm{y}(\mathrm{t})-\frac{1}{\gamma} \sum_{\mathrm{j}=1}^{\infty} \mathrm{K}_{\mathrm{ij}}(\mathrm{t}) \mathrm{u}_{\mathrm{j}}(\mathrm{t})+\frac{1}{\gamma}\left(-\phi_{\mathrm{i}}(\mathrm{t})+\sum_{\mathrm{j}=1}^{\infty} \mathrm{K}_{\mathrm{ij}}(\mathrm{t}) \psi_{\mathrm{j}}\right), \quad \mathrm{i}=1,2, \ldots
\end{array}\right.
$$

Hence, introducing functions

$$
\begin{gathered}
\mathrm{K}_{0}(\mathrm{t})=-\frac{1}{\sqrt{\gamma_{0} \gamma}} \mathrm{K}_{00}(\mathrm{t}), \quad \mathrm{K}(\mathrm{x}, \mathrm{s}, \mathrm{t})=-\frac{1}{\gamma} \sum_{\mathrm{i}, \mathrm{j}=1}^{\infty} \mathrm{K}_{\mathrm{ij}}(\mathrm{t}) \mathrm{X}_{\mathrm{i}}(\mathrm{x}) \mathrm{X}_{\mathrm{j}}(\mathrm{s}), \\
\mathrm{K}_{1}(\mathrm{x}, \mathrm{t})=-\frac{1}{\sqrt{\gamma_{0} \gamma}} \sum_{\mathrm{j}=1}^{\infty} \mathrm{K}_{0 \mathrm{j}}(\mathrm{t}) \mathrm{X}_{\mathrm{j}}(\mathrm{x}), \quad \mathrm{K}_{2}(\mathrm{x}, \mathrm{t})=\sqrt{\frac{\gamma_{0}}{\gamma}} \mathrm{K}_{1}(\mathrm{x}, \mathrm{t}), \\
\mathrm{q}_{0}(\mathrm{t})=\frac{1}{\sqrt{\gamma_{0} \gamma}}\left(-\phi_{0}(\mathrm{t})+\sum_{\mathrm{j}=1}^{\infty} \mathrm{K}_{0 \mathrm{j}}(\mathrm{t}) \psi_{\mathrm{j}}\right), \\
\mathrm{q}(\mathrm{x}, \mathrm{t})=\frac{1}{\sqrt{\gamma_{0} \gamma}} \sum_{\mathrm{i}=1}^{\infty}\left(-\phi_{\mathrm{i}}(\mathrm{t})+\sum_{\mathrm{j}=1}^{\infty} \mathrm{K}_{\mathrm{ij}}(\mathrm{t}) \psi_{\mathrm{j}}\right) \mathrm{X}_{\mathrm{i}}(\mathrm{x}) ;
\end{gathered}
$$

let's obtain a synthesized control for the initial problem in the following form:

$$
\left\{\begin{array}{l}
p_{0}(t)=K_{0}(t) y(t)+\int_{0}^{1} K_{1}(x, t) u(x, t) d x+q_{0}(t), \\
p(x, t)=K_{2}(x, t) y(t)+\int_{0}^{1} K(x, s, t) u(s, t) d s+q(x, t) .
\end{array}\right.
$$

As can be seen, $\bar{p}(x, t)=\left(p_{0}(t), p(x, t)\right)$ control is a functional defined on the set of the state function $\overline{\mathrm{u}}(\mathrm{x}, \mathrm{t})=(\mathrm{y}(\mathrm{t}), \mathrm{u}(\mathrm{x}, \mathrm{t}))$.

Strictly speaking, the control (31), which is obtained by the formal solution of the Bellman equation, can't be considered as optimal. Therefore, it is necessary to justify the obtained result and first of all show that it belongs to the class of admissible controls.

The boundary-value problem corresponding to the control (31) or the closed system takes the form:

$$
\frac{\partial u}{\partial t}=a^{2} \frac{\partial^{2} u}{\partial x^{2}}+\xi \frac{\partial^{3} u}{\partial t \partial x^{2}}+\int_{0}^{1} K(x, s, t) d s+K_{2}(x, t) y(t)+q(x, t),
$$




$$
\begin{gathered}
u(x, 0)=u^{0}(x), \\
\frac{\partial u(0, t)}{\partial x}=0, \frac{\partial u(1, t)}{\partial x}+\alpha u, \\
\frac{d y}{d t}=a_{0} u(1, t)+\left(b+K_{0}(t)\right) y(t)+\int_{0}^{1} K_{1}(x, t) d x+q_{0}(t), \\
y(0)=y^{0} .
\end{gathered}
$$

As a result, the process becomes self-regulating.

\section{Conclusions}

1. In a material with a heat conductive viscosity, the process of heat transfer is described by a third-order partial differential equation.

2. For each concrete admissible control from the class of quadratically summable functions, the considered boundary value problem has a unique generalized solution.

3. The Bellman equation solution is in the quadratic form.

4. The control parameter is found as a functional defined on the set of state functions.

5. The obtained results give an algorithm for solving the problem of synthesizing optimal control or constructing a controlling parameter in the form of feedback for various systems containing elements with distributed parameters.

6. In the future, various approximate methods for solving these problems can be considered.

\section{References}

[1] Bachoy, G. S. (1980). Ob odnoy zadache sinteza optimal'nogo upravleniya teplovym processom. Izvestiya Akademii nauk Moldavskoy SSR. Seriya: Fiziko-tekhnicheskih i matematicheskih nauk, 3, 29-36.

[2] Egorov, A. I. (2004). Osnovy teorii upravleniya. Moscow: FIZ MATLIT, 504.

[3] Mamedov, R. S. (2005). Optimal Control synthesis of distributed parameter system. The 1st International Conference on control and Optimization with Industrial Applications. Baku, 67-68.

[4] Mamedov, R. S., Karimov, V. A. (2010). Optimal stabilization problem for the oscillation proses an elastic rod. Continuous optimization and information - based technologies in the financial sector. Izmir, 130-133.

[5] Aida-zade, K. R., Abdullaev, V. M. (2012). On an approach to designing control of the distributed-parameter processes. Automation and Remote Control, 73 (9), 1443-1455. doi: 10.1134/s0005117912090019

[6] Ivanova, A. P. (2003). Upravlenie s obratnoy svyaz'yu dlya stohasticheskogo uravneniya teploprovodnosti. Izvestiya Akademii nauk. Teoriya i sistemy upravleniya, 5, 26-34.

[7] Ting, T. W. (1974). A cooling process according to two-temperature theory of heat conduction. Journal of Mathematical Analysis and Applications, 45 (1), 23-31. doi: 10.1016/0022-247x(74)90116-4

[8] Bachoy, G. S. (1988). Zadacha sinteza optimal'nogo upravleniya processom ohlazhdeniya slozhnyh sred. Matematicheskie issledovaniya, 101, 19-23.

[9] Mamedov, R. S. (2003). Sintez optimal'nogo upravleniya s minimal'noy energiey dlya sistem, soderzhashchih elementy s raspredelennymi parametrami. Problemy ispol'zovaniya ekonomicheskogo potenciala predpriyatiy v perekhodnom periode. Baku, 65-72.

[10] Egorov, A. I. (2006). Upravlenie sistemami s raspredelennymi i sosredotochennymi parametrami. Teoriya upravleniya i teoriya obobshchennyh resheniy uravneniy Gamil'tona-Yakobi. Ekaterinburg: Izd-vo Ural'skogo universiteta, 2.

[11] Egorov, A. I., Znamenskaya, L. N. (2005). Upravlenie kolebaniyami svyaznyh ob"ektov s raspredelennymi i sosredotochennymi parametrami. ZHVM i MF, 45 (10), 1766-1784. 